\title{
Discussions on Chinese Autocratic Monarchy System from the Perspective of Confucianism--Obtaining Benefits From One Source
}

\author{
Xiaoling $\mathrm{Hu}$ \\ Science and Technology College of Jiangxi University of Traditional Chinese Medicine, Nanchang, \\ 330006, China
}

Key words: Obtaining benefits from one source, Guan Zhong, autocratic monarchy system, Confucianism.

\begin{abstract}
The autocratic monarchy system had existed for more than two thousand years in Chinese history. Though it was a rotten sin, it also pushed the history forward, and played a huge positive role. In this paper, "obtaining benefits from one source (taking up farming and fighting)" was taken as an example to discuss the impact of Confucianism on Chinese autocratic monarchy system, so as to give comments faithful to the history on "obtaining benefits from one source" in an objective way.
\end{abstract}

\section{Introduction}

Autocratic monarchy system refers to a political system in which the authority centralized in the hand of the monarch or the supreme ruler. In Chinese history from the Qin Dynasty unifying six countries to the Revolution of 1911, and to the restoration of monarchy by Yuan Shih-kai, dynasties changed and the rulers had been changed for many times. Yet from the aspects of political model and economic model, the essence and nature of the system never changed, and the autocratic monarchy system survived more than two thousand years without change. "Kings have long arms", thus every Chinese feudal dynasty had trapped in feudal autocracy, stood still and refused to make progress, and hesitated to move forward. In despite of the "Wen-Jing Heyday" in the Han Dynasty, "Flourishing Kaiyuan Reign Period" in the Tang Dynasty, "the farming grounds in Suzhou and Huzhou were sufficient to support the whole country" in the two Song Dynasties, and other heydays, the essence and nature of feudal autocracy never changed. The small-scale peasant economy-dominating production mode made the national power of China decline, and fell behind the world farther and farther, so that it was invaded and ravaged by western powers in the late Qing Dynasty and modern times, and the masses had no means to live. Through investigation of the reasons and tracing the source, it was found that Confucianism had significantly influenced Chinese political system, and it could hardly absolve Confucianism from the blame. As said by Luxun: "The majority of Chinese history was comprised of ruthless exploitation, cruel massacre, warlord dogfight, invasion, etc.” [1]

\section{What is "obtaining benefits from one source"?}

"Obtaining benefits from one source" is an idiom originating from the Guanzi Guoxu: "If there is only one source to obtain benefits, the country is invincible." It was also stated in the Book of Shang Yang Weak People: "If there is only one source to obtain benefits, the country has abundant resources." Literally, it means "there should be only one source to obtain benefits, namely taking up farming and fighting”, which was put forward by Guan Zhong, a famous politician and reformer in Qi in the Spring and Autumn Period. Guan Zhong, also named Yi Wu and Jing Zhong, and styled Zhong, took the post of chief minister (prime minister) in Qi. During his forty-year tenure, he had been being cautious and conscientious, exerted his utmost effort to make the country prosperous, and spared no 
effort in the performance of his duty. He implemented the positive domestic strategy of "obtaining benefits from one source" and the diplomatic strategy of "honoring the king and driving off the barbarians”, making Qi develop and grow rapidly, and the people be strong and powerful, and helping Qi Huangong become the first power in the Spring and Autumn Period. Guan Zhong was rated as the "first minister in the Spring and Autumn Period". The original version of Guan Zhong's words goes as: "If there is only one source to obtain benefits, the country is invincible; if there are two sources, the effective strength of the army is halved; ...thus, the masses should be kept from superfluous wealth and other sources of obtaining benefits, which should be granted and taken away by the monarch; the monarch should decide the poverty and affluence of the masses. Thus, the masses will respect and support the monarch as the sun and moon, and love the monarch as parents." The "obtaining benefits from one source" from this excerpt actually intended to cut off the sources of income other than farming and fighting under the political context at that time, to restrict the masses and prosper the country. To put it other way, all people from members of the imperial house to the common people only should have one way to engaging in politics, business, and farming to obtain high position and great wealth. In a word, the country should control all channels of making a living of the common people, and manipulate the distribution of social wealth to centralize power and wealth in the hand of the minority via political, economic and legal means. Since the implementation of the policy of "obtaining benefits from one source", Qi had gradually developed and grown, and became powerful. In the Qin Dynasty, Shang Yang learned from Guan Zhong, and implemented the idea of "obtaining benefits from one source” to govern Qin, and also had made great achievements. Qin had become the leader among the powers, which laid a foundation for the first emperor of Qin unifying China.

\section{Influence of “Obtaining Benefits from One Source” on Chinese Autocratic Monarchy System from the Perspective of Confucianism}

During the Spring and Autumn Period and Warring States Period, feudal lords vied for the throne, and all the feudatory states recognized "development is a top priority". Thus, the political thought of national governance attracted abundant attention and was fully developed, and the thoughts of the Confucianism, Taoist, Mohist and Legalist were established successively. The first emperor of Qin unified China, which was overthrown by Liu Bang and Xiang Yu 15 years later. Then, wars between Chu and Han broke out. Finally, Liu Bang won, and founded the Han Dynasty. In the Han Dynasty, with the unification, political stability and economic boom, the unification of ideologies and cultures was put into consideration. Dong Zhongshu, a famous ideologist, philosopher, politician and education in the Han Dynasty, put forward "heaven-human induction", the theory of "great unification", and "banning a hundred schools of thoughts, and commending the six Confucian classics" in the Measures for Recommendation of Able and Virtuous Men. In the opinion of Dong Zhongshu, "the basis for the objective laws is the vast void or absolute space", and the nature and human affairs both are subject to the mandate of heaven. Thus, the political order and political thought reflecting the mandate of heaven should be unified. The Confucianism of Dong Zhongshu defended the centralization ruling of the Emperor $\mathrm{Wu}$ of Han Dynasty, and made a certain contribution to the social, political and economic stability at that time. Besides, Dong Zhongshu wrote the Outspreadlaces of the Spring and Autumn Annals, which focused on Confucianism, and touched the thoughts of the Taoist, Legalist and the Yin-Yang School, and with which he created the situation of "banning a hundred schools of thoughts, and paying supreme tribute to Confucianism". There are different viewpoints on the origin of monarch. It was held in the Outspreadlaces of the Spring and Autumn Annals-Yao, Shun, Tang and King Wu of Zhou that: "the heaven authorized Yao and Shun to rule the world, and Yao and Shun received instructions from heave to rule the world." It was held in the Commentary of Zuo-The Fifteen Year of Wen that: "making discipline rite in consistency with the mandate of heaven is a natural law", in which the validity and legality of monarchical power was attributed to "heaven", and it was held that "heaven" conferred monarch the 
monopoly and absolute power. At last, the Confucians represented by Dong Zhongshu shaped monarch into the supreme lawmaker and supreme power executor of country by the theory of "Divine Right of Kings", and validated the dominion of monarch to the masses. This theory had been implemented by the ruling class since then, and had established the position of Confucianism in Chinese history and culture.

To further consolidate the ruling of feudal rulers, Dong Zhongsu also creatively proposed to validate "changing monarch", "monarch ruling officials" and "monarch governing the masses". "The basis for the objective laws is the vast void or absolute space, and as long as the void or absolute space is not changed, the objective laws will never change" [2]. The kingship theory of "rebelling against emperor rather than kingship" was put forward. The operation of monarchy was constantly adjusted by extreme means such as revolution and fight, which always ended with the reestablishment of monarchy. The internal regulation mechanism of “changing monarch" didn't violate the monarchy system, but aimed at those fatuous rulers retroacting, violating principles, and damaging the overall interests of the ruling class to consolidate the autocratic monarchy system. Confucianism completed and developed Chinese autocratic monarchy system by itself little by little, of which the influence can be said to be farreaching. Under this context, Guan Zhong, who was deeply influenced by Confucianism, put forward the idea of "obtaining benefits from one source". This idea seemed to emerge for the ruling of the feudal group, became the fundamental national policy for governing in the following dynasties, and put Chinese nation into the "Guan Zhong Trap" for thousands of years again and again. No matter how dynasties changed or the situation changed, the governance form of the country never changed. Monarchy persisted, and power and interests were centralized in the hand of one person. This is why "a state cannot work without the king”. Afterwards, Shang Yang, Wang Anshi, and Zhang Juzheng all followed the management theory of "obtaining benefits from one source” while administering state affairs, ensuring national security, and assisting the monarch. Some officials in the late Qing Dynasty, including Zeng Guofan and Li Hongzhang, also implemented the strategy of "obtaining benefits from one source" in leading troops and carrying out the westernization movement. It is thus clear that "obtaining benefits from one source" exerted a huge farreaching influence on Chinese autocratic monarchy system and feudal dynasties.

\section{Treating Guan Zhong and His Theory of “Obtaining Benefits from One Source” dialectically}

Gan Zhong, "the first minister in the Spring and Autumn Period", made great achievements in assisting ruler in country governing. Besides, his thoughts also exerted farreaching influence on Chinese culture. Confucius exclaimed in front of his followers: "without Gan Zhong, we may have become like barbarians with disheveled hair and in cardigan”. In combination with the historical background, this sentence was interpreted into: "If there is no Guan Zhong, I am afraid we may have become like barbarians with disheveled hair and in cardigan”. Actually, Confucius meant to praise and affirm the contribution of Gan Zhong of assisting Qi Huangong in honoring the king and driving off the barbarians. The "barbarians" mean the northern ethnic groups at that time, and disheveled hair and cardigan were their style. Since Guan Zhong assisted Qi Huangong in resisting the harassment of the northern ethnic groups, and defended the Zhou royal court and kingdoms in the Central Plains, Confucius stated this words to praise Guan Zhong. It is thus clear how significant the influence of Guan Zhong was. The praise made by Confucius, however, was for Guan Zhong's capability of administering state affairs only. In the viewpoint of Confucius, Guan Zhong's ability was superior to his moral character, and Guan Zhong couldn't be called a man of noble character in respect of "thrift" and "ritual". As recorded in the Analects of Confucius: Confucius said: "Guan Zhong was less tolerant!” or: "Was Guan Zhong frugal?” It was mentioned in the Spring and Autumn Annals that Bao Shuya partnered with Guan Zhong in business, but Guan insisted to take a large share of interests for the reason of filial piety to his mother. He escaped from battlefield when serving the army, and indulged in a life of pleasure and comfort during his tenure of minister by taking several concubines. Of course, these stories were regarded as personal virtue and trifles in ancient times. Cao Cao said 
"only using the talented, regardless of the trifles". It means that we should not expect things to be perfect in treating outstanding figures. Thus, we should not ignore nor hide Guan Zhong's moral defects while affirming his ability. After all, nobody is perfect, and gold can't be pure. In a word, we should objectively comment historical figures.

About the idea of "obtaining benefits from one source” put forward by Guan Zhong, there are two entirely different viewpoints. The side affirming Guan Zhong held that "obtaining benefits from one source” helped prevent rich merchants from cornering the market, which would cause gap between wealthy and poverty, and form a situation where several economic giants monopolize and manipulate the economic lifeline of the country. Under the guidance of national policy, people could advance to the established aims, and realize personal ideals and ambitions through the efforts. It benefited the nation and the people, and finally realized the aim of prospering the nation and strengthening the people. Besides, the idea of "obtaining benefits from once source" also is of great practical significance and is widely applied in the contemporary era. In 2012, for example, Mr. Meng Wanzhou, CFO of Huawei, said the success of Huawei rested with the management principle of "obtaining benefits from one source". He explained, the idea of "obtaining benefits from one source" can be interpreted to be that limited resources can be used for limited purposes, and Huawei can maintain prolonged stability only by using all resources to serve its strategy to make strategic breakthrough". Huawei won universal praise for its success in the industry in China. It is the typical case of successful practice of the management idea of "obtaining benefits from one source" in business management, and reflects the positive practical significance of Guan Zhong ideas in modern times. The side denying Guan Zhong held that the idea of “obtaining benefits from one source” was the tool of rulers to control and exploit the common people, and served and beatified the rulers and feudal dynasties in ancient times. The supreme rulers controlled all channels of survival and development, and implemented policy of keeping the people in ignorance and weakening. No one could climb or ascend unless he depended on his superior. In this way, the stiff hierarchies were established to enhance the personal bondage between the lower class and the higher class. The theory of "obtaining benefits from one source" enhanced the ruling of feudal rulers, but society and economy declined for this reason, the national treasury became bare, people became poor and weak, and the country was invaded and ravaged by western powers at last.

\section{Conclusion}

Chinese autocratic monarchy system emerged under specific social and historical conditions, and had survived for more than two thousand years. Though it was foulest and negative, it also played a huge positive role. The feudal autocratic monarchy system was just like a fancy gown of the feudal ruling circles, and the series thoughts of Confucianism were its soul. They supplemented each other to constitute the two main bodies in the ancient political history of China. Today, the internet technology develops rapidly, and the education pattern has had earth-shaking changes, but Confucianism is still a valuable ideological treasure of the Chinese nation. We should absorb the quintessence and discard the dross, and treat and apply Confucianism dialectically, which is of certain guiding significance to our work and learning.

\section{References}

[1] Li Shenzhi. Chinese Cultural Tradition and Modernization. Strategy and Reason, 2000(41).3-6.

[2] Luxun. Jiwaiji Gleanings-The Same String Had Been Sung. Completed Works of Luxun, Volume 7.

[3] History of the Han Dynasty—Biography of Dong Zhongshu.

[4] Qian Mu. New Discussions on Chinese History. Beijing: SDX Joint Publishing Company, 2001. 
[5] Zheng Zuting. Thoughts Origin and Basic Contents of Marx's Oriental Autocratic System Theory. Journal of Xiangtan University, 1995, (5).

[6] Liang Qichao. Study on Chinese Central Monarchy Originating from Yao and Shun. Ce-drinking Room Collected Works. Beijing: Zhonghua Book Company, 1936.

[7] Fan Wenlan. On Reasons for Continuity of Chinese Feudal Society. Selected Works of Fan Wenlan Historical Theses. Beijing: China Social Sciences Publishing House, 1979. 